\title{
The assessment of high velocity multi-impact damage in steel fiber reinforced cementitious composite panels
}

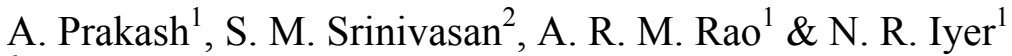 \\ ${ }^{I}$ CSIR-Structural Engineering Research Centre, India \\ ${ }^{2}$ Department of Applied Mechanics, IIT Madras, India
}

\begin{abstract}
This paper presents a high velocity impact damage assessment of $100 \mathrm{~mm}$ thick steel fiber reinforced cementitious composite (SFRCC) panels of size $300 \mathrm{~mm} \times 300 \mathrm{~mm}$. The panels are tested using in-service munitions in field firing range under high velocity impacts of $5.56 \mathrm{~mm}$ and $7.62 \mathrm{~mm}$ calibre projectiles. Three consecutive normal impacts are made on each of the SFRCC panel within the damage zone of previous hits. The details of impact tests, procedure adopted for multi-impact damage assessment are described in the paper. Measurements are taken for depth of penetration, location of cracks, and crater sizes under first hit, as well as after consecutive hits. In order to quantify the damage in SFRCC panels under multiple impacts, both non-destructive testing (NDT) and destructive methods are adopted. For quantitative assessment of the internal overlapping damage zones, NDT using ultrasonic pulse velocity (UPV) measurement on a square grid spacing of $20 \mathrm{~mm}$ is carried out. Internal overlapping of damage zones due to multi-impacts on SFRCC panels are identified in non-destructive manner. To verify the effectiveness of the NDT method in multi-impact damage assessment, few SFRCC panels are dissected, using concrete cutting machine. Numerical simulation is also carried out to predict damaged area in the panels under multi-impacts. The damage contours obtained from numerical simulations are found to match with the damage zones detected using NDT method.

Keywords: high velocity impact, damage assessment, NDT, steel fibre reinforced cementitious composite panels, $5.56 \mathrm{~mm}$ and $7.62 \mathrm{~mm}$ calibre, numerical investigation, RHT, depth of penetration, crater.
\end{abstract}




\section{Introduction}

Inclusion of steel fibers in concrete (or cementitious matrix) enhances the toughness which helps in energy absorption, tensile strength that helps in controlling micro-cracks induced due to extreme loading conditions like blast and impact (Lankard [1]). It has been reported that the fiber reinforced concrete with $1-3 \%$ of fiber (by volume) offers better crack resistance as compared to the RCC. But, when fiber volume is more than $2 \%$, it becomes difficult to mix them along with the concrete mix, because of the formation of fiber balls. Hence, techniques have been developed (Naaman and Homrich [2]) in which higher fiber volumes such as, 3 to $30 \%$ depending upon size and type of fiber can be infiltrated with cement sand slurry. Such high volume of fibers is needed in the situations, when a structural element has to withstand extreme loading repeatedly. The main role of fibers in concrete is to bridge the cracks, increase post peak resistance and to provide better energy absorption (Parameswaran [3]).

Due to these advantages of fiber reinforcement better spall resistance, high energy absorption without losing structural integrity can be achieved under impact loading. When a bullet (small calibre projectile) hits the composite panel, it tries to penetrate through. But due to resistance offered by composite panel, bullet gets defeated eventually if adequate impact resistance is available. However, it can cause certain amount of damage to the panel classified such as spalling, perforation, delamination, cracking, scabbing, perforation and fragmentation (Maalej et al. [4]). The challenging task before designers or researchers is that how to assess the impact damage occurred in the panels? Further questions arise that, how to quantify the damages when multi-hits are made in the close vicinity of previous hits?

Of various types of ultrasonic techniques reported by Acebes et al. [5] and Chaix et al. [6] for non destructive technique (NDT), through transmission ultrasonic scan is considered suitable for SFRCC panels with high steel fibre volumes. Because of the loss of signals due to multiple reflections it becomes difficult to produce a clear image as in case of impact echo method. Aggelis and Shiotani [7] have carried out repair evaluation of concrete cracks using surface and through-transmission wave measurements. Breysse et al. [8], through NDT, found a practical and efficient way to assess the structural state of existing reinforced concrete structures. However, from such assessment it is difficult to interpret because of qualitative nature, hence structural engineers often need a quantitative assessment. From the selected review of literature, it is observed that information on the damage assessment in SFRCC panels subjected to multi-impacts is not adequate. Existing researches by Maalej et al. [4] and Luo et al. [9] conducted on impact behaviour of fibre composite panels are limited to the measurements for crater size on surface and depth of penetration along with visual observations on the cracking available in tested panels. Recent studies by Leppanen [10], Nyström and Gylltoft [11] etc., have focused on predictions based on numerical simulations using concrete model of Riedel et al. [12]. Some of the above studies have showed numerical simulation of spalling and scabbing on front and rear faces. 
This paper presents impact damage assessment methodology for SFRCC panels subjected to multi-hits, by adopting a three prong strategy. To understand the progressive damage in the SFRCC panels, numerical simulations are also carried out. Results are found to match reasonably well with experimental results. Due to limitation of space, only selected results are provided in this paper to demonstrate the approach followed for damage assessment.

\section{Non-destructive methods for detection of impact damage}

Diagnostic methods that have emerged over the last decades have led to improved understanding of fracture mechanisms and long-term performance of concrete (Sanjeev et al. [13]). Mainly four types of techniques are used to evaluate damage in concrete: visual observation, X-ray examination, microscopy, and non-destructive testing. The visual observation is most widely used forms of non-destructive evaluation. Among these methods nondestructive testing (NDT) methods have been proved to be very valuable and practical, due to quicker inspection and evaluation of damage and deterioration in concrete structures.

\subsection{Ultrasonic pulse transmission methods}

The most frequently used method is ultrasonic pulse velocity (UPV) which measures the transmit time of the fastest wave between two transducers attached to the opposite surfaces of the specimen. Of all the non-destructive methods, ultrasonic methods offer a distinct advantage of being able to detect the interior deterioration (even after the occurrence) at relatively low cost and without causing any new damage (Panzera et al. [14]). There are two types of waves: compressive waves and shear waves. For cementitious material like, PCC, HPC, UHPC etc., compressive waves are most frequently used for ultrasonic testing.

Steel fiber reinforced cementitious composite and concrete are heterogeneous material. Therefore suitable pulse frequency needs to be chosen for obtaining correct pulse velocity. The pulse velocity is independent of the dimension or geometry of the test object (Popovics et al. [15]). In the present study, to avoid the error in UPV measurements, the SFRCC panel having smallest dimension more than the wavelength of the ultrasonic vibrations are adopted.

\section{Experimental programme}

The impact tests on SFRCC panels are conducted using in-service munitions to obtain realistic impact performance of the SFRCC panels. Later investigations are carried out on tested panels using NDT methods for determining the internal damage due to impact tests.

Materials used in the preparation of SFRCC panels include $10 \%$ by volume of hooked end steel fibres having $0.45 \mathrm{~mm}$ diameter and $30 \mathrm{~mm}$ length (aspect ratio 66 , cement of OPC-53 grade, fine sand (less than $4.75 \mathrm{~mm}$ sieve size), super plasticizer SP-430 and potable water. C:S:w/c in proportion as 1:1:0.4 with 
SP-430 as $0.125 \%$ volume of cement is added. Average tensile strength of hooked end steel fibres obtained based on single fiber pull out test as $1100 \mathrm{MPa}$. The inputs for material of projectiles namely, Cartridge brass jacket and Lead core for $5.56 \mathrm{~mm}$ projectile, and Gilding copper jacket and steel core for $7.62 \mathrm{~mm}$ projectile, are adopted from material library of AUTODYN [18] software.

Table 1: Mechanical strength of materials after 28 days.

\begin{tabular}{|c|c|c|c|}
\hline Material & $\begin{array}{c}\text { Unconfined } \\
\text { Compressive }\end{array}$ & $\begin{array}{c}\text { Uniaxial } \\
\text { Tensile }\end{array}$ & Flexural \\
\hline SIFCON (MPa) & 106.2 & 18.62 & 37 \\
\hline Plain Slurry & 59.2 & 3.14 & 3.0 \\
\hline
\end{tabular}

\subsection{Geometry of the panels and projectiles}

The geometry of SFRCC panels and projectiles used impact tests are shown in fig. 1. The plan dimensions $(300 \times 300 \mathrm{~mm})$ of the SFRCC panels are adopted considering the ease in handling during impact tests.

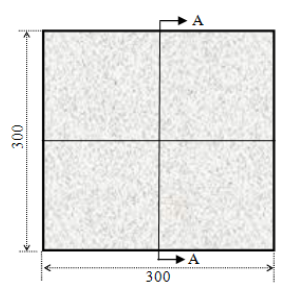

SFRCC Panel

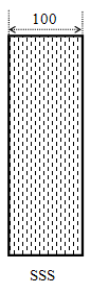

a) Calibre $5.56 \mathrm{~mm}$

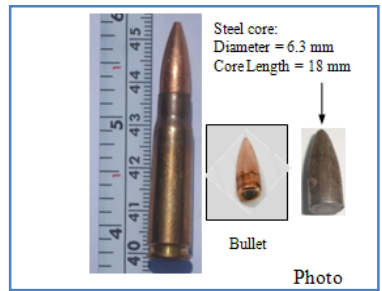

(b) Calibre $7.62 \mathrm{~mm}$

Figure 1: Geometry details of SFRCC panels and projectiles used.

The kinetic energies of $5.56 \mathrm{~mm}$ and $7.62 \mathrm{~mm}$ calibre projectile are obtained as $1.7 \mathrm{~kJ}$ and $2.1 \mathrm{~kJ}$ respectively.

\subsection{High velocity impact tests}

The experiments have been conducted using in-service ammunitions and military weapon. The experiments are conducted in controlled conditions by keeping weapons, projectiles, muzzle distance, test setup to hold the panels unchanged. Schematic test set-up used for impact tests on SFRCC panels is shown in fig. 2. 


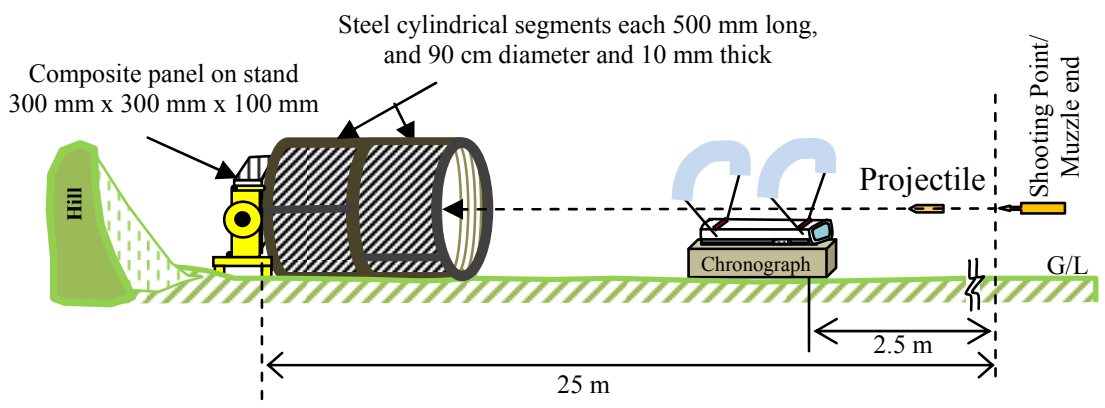

Figure 2: Schematic test set up for impact tests on SFRCC panels.

Few selected panels made of SIFCON and having $100 \mathrm{~mm}$ thickness are considered in this paper for impact damage assessment. Initially one panel of each type was tested under singe hits and then measurements were taken under single hit (fig. 3). The depth of penetration, crater dimensions and cracking status was recorded. Later to determine the impact resistance of similar panels under multi-hit scenario two to three additional impacts were made on the same panel, closer to the previous hits. The measurements are taken after impact tests for depth of penetration and crater dimensions.

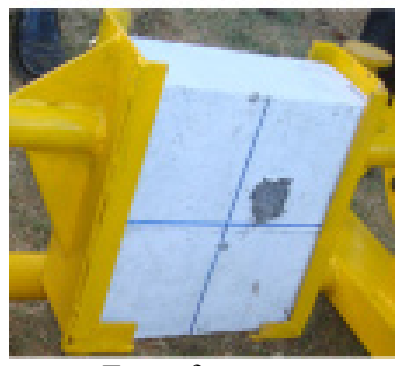

Front face

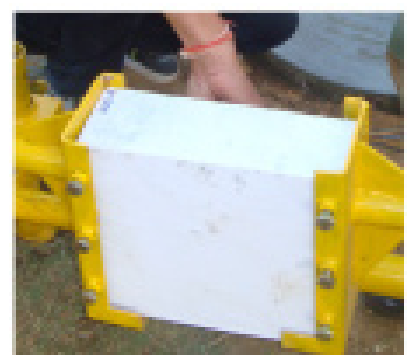

Back face

Figure 3: Panels after single hit of projectile.

\subsection{NDT on SFRCC panels using UPV measurements}

As per IS 13311 (Part-1): the UPV measurements are taken to assess damage in impact tested SFRCC panels [16]. Direct transmission method is adopted to minimize the loss of transmission through high concentration of steel fibres.

Standard procedure using PUNDIT equipment is used for the ND evaluation. Before taking the UPV readings the equipment is calibrated by means of specific reference bar (fig. 4(a)). After the calibrating the transducers $(54 \mathrm{kHz})$ and test set up number of UPV readings are taken for damaged SFRCC panels on a grid spacing of $20 \mathrm{~mm}$. To avoid any air gap suitable couplant (i.e. grease) is used and, readings are taken on all the grid points. Checks are made to verify the repeatability of UPV readings. To avoid generation of noise signals and errors in 
measurements the transducers are firmly pressed onto the surface of the panels without shaking the transducers while taking each reading. The fig. 4 (b) shows the measurement of UPV in the SFRCC panels. The simple expression is used for UPV determination, $\mathrm{V}=\mathrm{L} / \mathrm{T}$; Where, $\mathrm{V}$ is pulse velocity $(\mathrm{m} / \mathrm{s}), \mathrm{L}$ is length $(\mathrm{m})$, and $\mathrm{T}=$ Effective time $(\mathrm{sec})$.

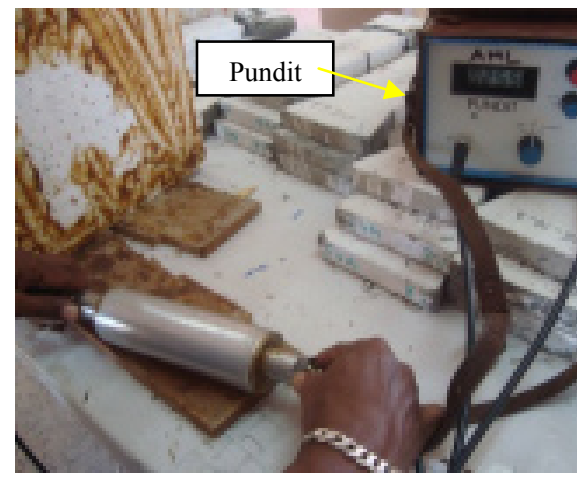

(a) Calibration

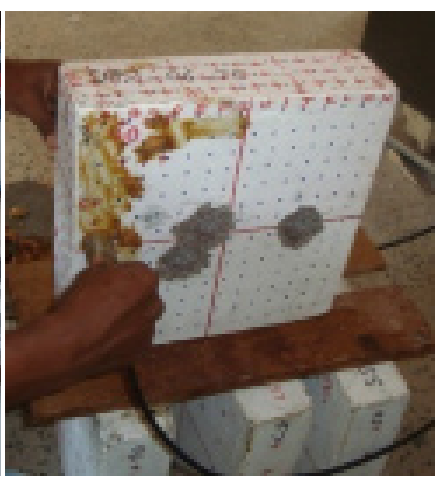

(b) Measurement

Figure 4: Measurement of ultrasonic pulse velocity on tested SFRCC panels.

\subsection{Destructive investigations on SFRCC panels}

To correlate the UPV measurements with the actual internal damages few selected panels with $10 \%$ fibre, are cut with the cutting machine as show in fig. 5. The cutting is done with the help of diamond tip blade at a speed of $1500 \mathrm{rpm}$.

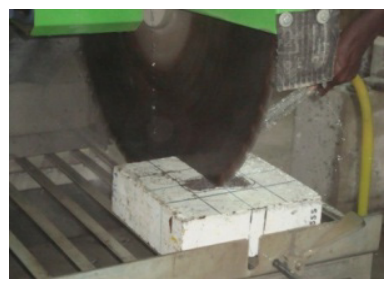

Cutting of panel

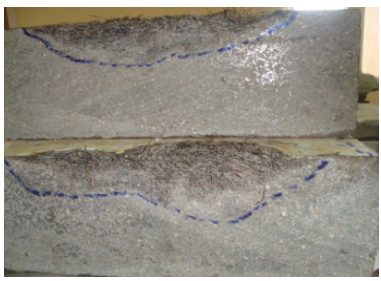

Panel $34\left(\mathrm{~V}_{\mathrm{f}}=10 \%\right)$

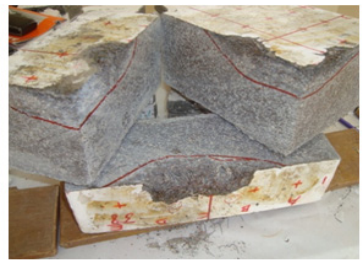

Panel $38\left(\mathrm{~V}_{\mathrm{f}}=10 \%\right)$

Figure 5: Cutting of SFRCC panels tested under $7.62 \mathrm{~mm}$ projectile.

The cross-sections of SFRCC panels after cutting are shown in fig. 5. It is observed that there is no visible cracking in the infill layers. It can be seen that the influnece zone due to multi hit gets overlapped although at surface the craters seems to be separate from each other. Hence it is proved that the SFRCC panels have resisted multihits without losing it structural integrity. 


\subsection{Results of non-destructive investigations}

The ultrasonic pulse velocity corresponding to damaged regions differs with that of far off regions within the panel. Therefore a relative assessment can be done based on the variation in UPV readings. In this paper the UPV values have been normalized with respect to highest value of UPV and lowest value of the UPV. Normalized UPV values are obtained for a composite panels based on the formula as follows:

$$
\begin{gathered}
\text { Normalized } U P V=\left(V-V_{\min }\right) /\left(V_{\max }-V_{\min }\right) \\
\text { Damage index }=1-\text { Normalized UPV }
\end{gathered}
$$

UPV measurements taken at grid spacing of $20 \mathrm{~mm}$ and the normalized damage contours are obtained as shown in fig. 6 . Based on the above expressions defined for damage the percentage cumulative area of contours under the damage index values are given in table 2. It is observed that the contour with $50 \%$ reduction in UPV reading matches with visible damaged area inside the panel as verified by dissected SFRCC panels.

The damage index value of as 0.5 means that within that contour the material has $50 \%$ strength as compared to intact strength. In this way the damaged area under normalized contours is determined which is correlated with numerical responses or destructive measurements on dissected panels.

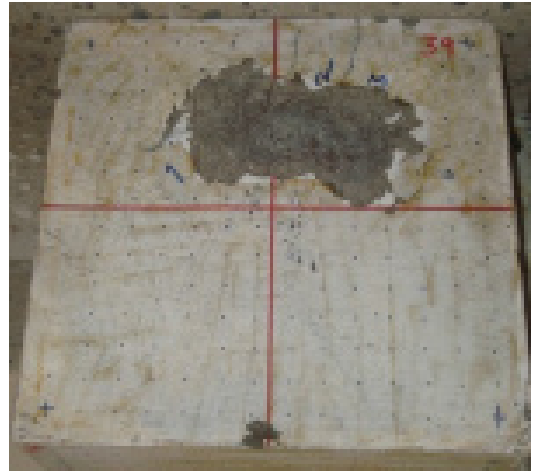

PID 39 (10\% fiber volume)

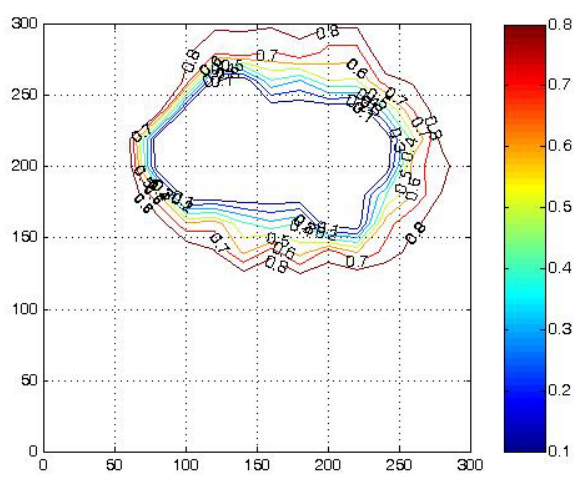

Computed normalized contours

Figure 6: Normalized contour for damaged zone under three hits.

Table 2: Damaged area under three hits of projectile.

\begin{tabular}{|c|c|c|}
\hline \multirow{2}{*}{ Damage } & \multicolumn{2}{|c|}{ Cumulative damaged area (\%) } \\
\cline { 2 - 3 } & Panel 34 under 7.62 mm & Panel 39 under 7.62 mm \\
\hline 0.9 & 10.30 & 13.06 \\
\hline 0.8 & 12.21 & 14.80 \\
\hline 0.7 & 14.12 & 16.53 \\
\hline 0.6 & 16.08 & 18.21 \\
\hline 0.5 & 19.67 & 20.39 \\
\hline
\end{tabular}


The damage index and damaged area for three panels are defined in table 2. It indicates the damaged region within encircled contour having reduction in UPV equal to or more than the normalized contour value. For example, damage index 0.5 means the percentage of impact damaged area to that of whole panel area under multi hits. Within this normalized contour value the UPV gets reduced by $50 \%$ or more with respect to UPV of far-off region within the panel. It does not indicate reduction in the impact resistance of SFRCC panel.

\section{Numerical simulations on damage assessment}

\subsection{Finite element model of target and projectile}

Three dimensional finite element models are developed for numerical prediction on the impact damage in SFRCC panels. 3D solid element based on Lagrangian approach is used in the FE mesh are shown in fig. 7. From mesh convergence study, the finite element mesh size used for target is $1 \mathrm{~mm}$ near the center of impact and grading is carried out for the far-off regions. Grading is done to avoid high compuational cost and requirment of more computational resource. Both the core and metal jackets of ogive nosed projectiles are modeled to simulate effect of jacket on impact resistance of SFRCC panels (fig. 3).

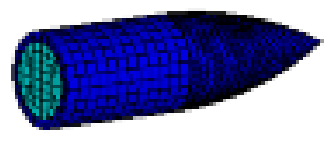

Metal jacketed projectile

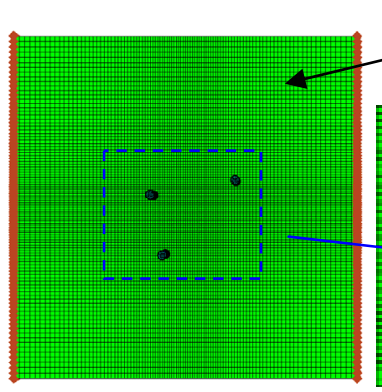

SFRCC Panel
SIFCON

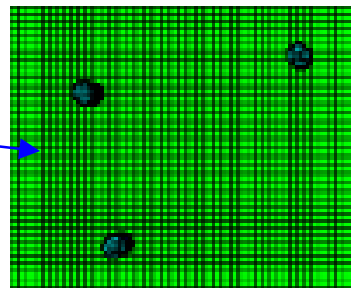

Zoomed view

Figure 7: Finite element mesh for projectile and target panels.

\subsection{Material model used for cementitious composites}

Dynamic strength analysis and modelling of cementitious materials like concrete or fiber reinforced concrete is an ever challenging field of research. Experiments for relevant loading rates and pressures reveal that concrete exhibits a complicated nonlinear behaviour that is difficult to capture in a single constitutive model. Nonlinearity in the concrete evolves due to the internal processes resulting there from, such as porous compaction, complex strain localization, micro-cracking, cell wall buckling and plasticity, etc. These 
micromechanical effects need a homogenized macro-mechanical description that will involve the appropriate interdependence between stress, strain, plastic strain, strain rate, damage and failure in order to be implemented.

In the present study, RHT concrete model is used with modified material input based on experimental tests, to represent SFRCC strength, failure/damage behaviour. For $7.62 \mathrm{~mm}$ projectile steel strength and failure behaviours are modelled using modified Johnson Cook models.

\subsubsection{RHT model for concrete}

The equation of state represent pressure-density curve used for SFRCC as given in in-built library of AUTODYN [18] is depicted in fig. 8 (a).

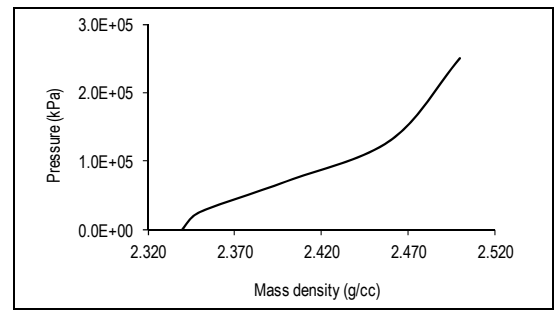

(a) Used for SFRCC (AUTODYN)

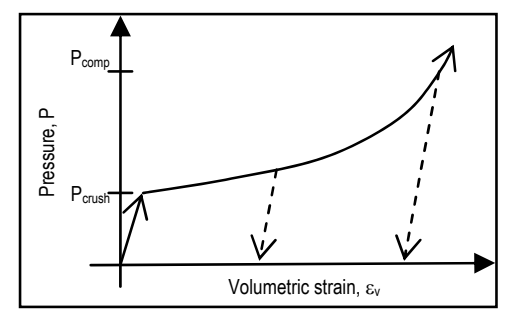

(b) Pressure--volumetric strain curve

Figure 8: Equation of state for pressure dependent material.

A schematic description of the volumetric compaction model is shown in fig. 8 (b). During dynamic compression the pore crush pressure and compaction pressure play an important role. The porous compaction starts at a pressure value corresponding to the pore crush pressure, below which the model is elastic. On the initiation of pore collapse, a significant reduction in the effective bulk modulus is observed as the related micromechanical effects reduce the volumetric stiffness of the material.

The RHT strength model is expressed in terms of three stress limit surfaces; the initial elastic yield surface, the failure surface and the residual friction surface (Borrvall and Riedel [17]). To model SFRCC it can be homogenized as one material instead of modelling each of the discrete fibre and its bond to the surrounding concrete. The material properties for SIFCON layer having $10 \%$ fiber are modified for compressive strength 106.2 $\mathrm{MPa}$ and uniaxial tensile strength as $18.42 \mathrm{MPa}$. The ratio for tensile to compressive strength is 0.17 and shear strength to compressive strength is taken as 0.25 .

\subsubsection{Johnson Cook model}

This constitutive model is used to model the strength behaviour of ductile materials that are subjected to large strains, high strain rates and high temperature. For each related phenomenon namely, strain hardening, strain rate and thermal softening; an independent term is created in this model. This constitutive model is relatively easy to calibrate since it allows isolation of 
various effects. Various material models used for the numerical model are given in table 3. Elimination of highly deformed elements is carried out using erosion criteria based on geometric strain criterion. However inertia due to eroded elements is retained at respective nodes.

The input values given in material library for Steel 4340 are used for core of $7.62 \mathrm{~mm}$ projectile. For jacket cartridge brass as provide by the AUTODYN [18] material library are used. Comparisons are made between numerically predicted and experimentally obtained impact responses. Relative impact performances based on impact tests are described for composite panels with different sandwiched layers. It is found that the composite panel having $50 \mathrm{~mm}$ thickness was perforated during impact test and the same was predicted numerically also (fig. 9). Also the crater dimensions and depth of penetrations measured experimentally was nearly matched with the numerical results.

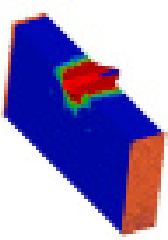

$50 \mathrm{~mm}$ thick

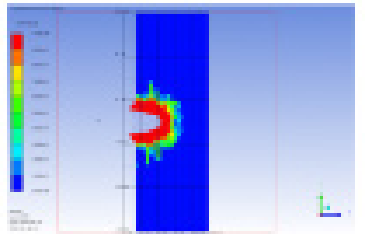

$100 \mathrm{~mm}$ thick

Figure 9: Damage in SFRCC panel under single hit of $7.62 \mathrm{~mm}$ projectile.

A panel made of plain mortar was fractured by single impact of $5.56 \mathrm{~mm}$ calibre projectile. Few selected responses as predicted numerically and obtained experimentally are shown in table 3 .

Table 3: Comparison of experimental and numerical results.

\begin{tabular}{|c|c|c|c|c|c|c|c|}
\hline $\begin{array}{c}\text { Panel } \\
\text { thickness } \\
\mathrm{mm}\end{array}$ & $\begin{array}{c}\text { Impact } \\
\text { velocity } \\
\mathrm{m} / \mathrm{s}\end{array}$ & $\begin{array}{c}\text { Projectile } \\
\text { mass } \\
\mathrm{g}\end{array}$ & $\begin{array}{c}\text { Kinetic } \\
\text { energy } \\
\mathrm{kJ}\end{array}$ & $\begin{array}{c}\text { Exp. } \\
\mathrm{mm}\end{array}$ & $\begin{array}{c}\text { Num. } \\
\mathrm{mm}\end{array}$ & $\begin{array}{c}\text { Exp. } \\
\mathrm{mm}\end{array}$ & $\begin{array}{c}\text { Num. } \\
\mathrm{mm}\end{array}$ \\
\hline 100 & 900 & 4.16 & 1.70 & 36.6 & 30.6 & 60.0 & 58.2 \\
\hline 100 & 720 & 8.00 & 2.10 & 46.0 & 43.0 & 55.0 & 58.0 \\
\hline 50 & 900 & 4.16 & 1.70 & Perforated & Perforated & 20.0 & 40.0 \\
\hline
\end{tabular}

It is found that the crater dimensions do not vary much for multi-hit scenario. Further the crater shapes are found to match closely with that on the surface of the tested panels (fig. 10 (a) and (b)). Numerical simulation using 3D finite element model is also carried out to simulate the sequence of hits as was made during impact tests for $100 \mathrm{~mm}$ thick panels and damage zones corroborate 
closely with the experiments. The numerically obtained crater dimension and depth of penetrations are found to match well with that of experimental results. Dissipation of kinetic energy of projectile under each hit is shown in Fig. 10 (c).

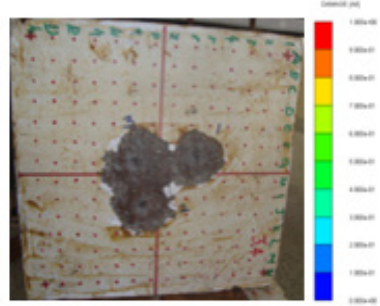

(a) Experimental

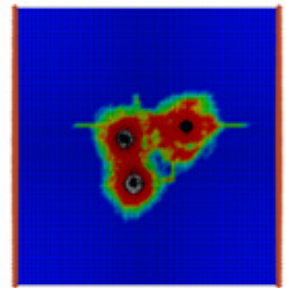

(b) Numerical

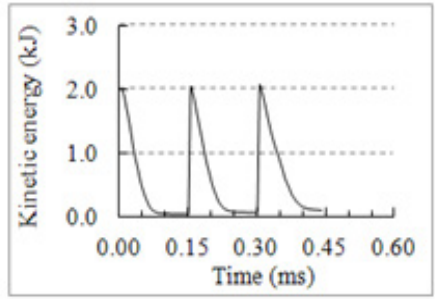

(c ) KE dissipation

Figure 10: Multi-impact damage in SFRCC panel after three hits.

Comparison of overlapping damage zones in SFRCC panel is shown in fig. 11. Numerical simulation based on axisymmetric model is also carried out and it is observed that for a $10 \%$ steel fiber in $100 \mathrm{~mm}$ thick panel two hits of $5.56 \mathrm{~mm}$ are resisted safely, whereas for $7.62 \mathrm{~mm}$ projectile the panel found to got perforated under the second hit.

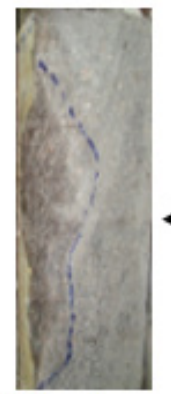

(a) Experimental

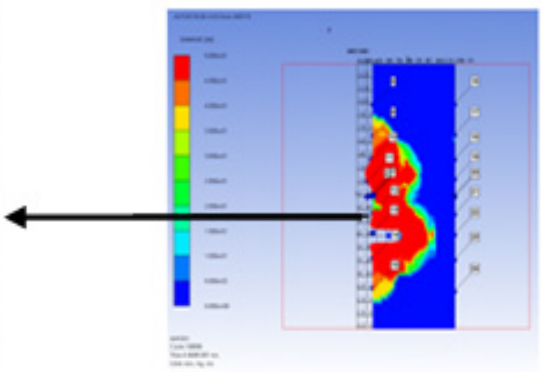

(b) Numerical

Figure 11:Comparison of damage under multi-impact.

For simulation of multi hit a time delay of $150 \mu$ s is set between the consecutive hits. This time delay is corresponds to the time instant when projectile kinetic energy gets dissipated. The damage contours obtained from the numerical simulation nearly match with the actual damage zone on the surface of panels (fig. 12 (a)). It is observed that if the impact hits are within 10D of projectile the damage zone overlaps (fig. 12 (b)) and for greater distances the damage zones remain separated (fig. 12 (c)). Hence it is inferred that the impacts on the SFRCC panels within 10 times the calibre diameter will be considered the case of multi hit. 


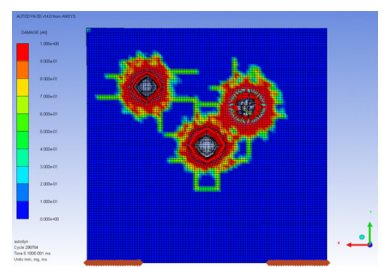

(a) Panel with multi-hits

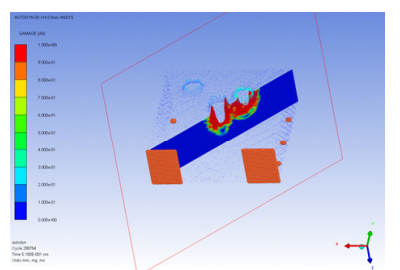

(b) hits within 10 times of calibre dia.

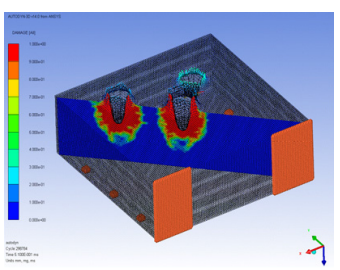

(c) hits at $>10$ times calibre dia.

Figure 12: Damage contours under multi-hits of $7.62 \mathrm{~mm}$ calibre.

\section{Conclusions}

In this paper a three prong simple methodology is presented for damage assessment of SFRCC panels under single hit and also for repeated impacts. The following conclusions can be drawn based on the observations and results of the presented study:

- Non destructive method using ultrasonic pulse velocity found to be useful in the determination of the internal impact damages in panels with $10 \%$ fibre volume. The qualitative assessment of damage has been verified with the help of numerical simulations.

- From numerical simulation it is found that the damage region can accurately be predicted under multiple impacts by taking due care for accumulated damage under previous hits.

- It is determined numerically that, if the impact locations are separated by a distance of 10 times the calibre diameter of projectiles, the damage regions inside the panel do not overlap each other and hence exert no mutual influence.

- Based on multi-hit simulation using axisymmetric model of impact on SFRCC panels with $100 \mathrm{~mm}$ thickness, it is found that the panel could resist safely, the two hits of $5.56 \mathrm{~mm}$ projectile at the same location. But it was perforated under second hit of $7.62 \mathrm{~mm}$ projectile.

- Normalized contours based on UPV measurements taken on the grid of $20 \mathrm{~mm}$ spacing indicated that the 50\% reduction in UPV reading with respect to the maximum UPV within the panel correlates with the visible damage in the panel.

\section{Acknowledgements}

The help rendered by staff of AML, ACTEL and SVG, during impact tests the SFRCC panels is gratefully acknowledged. The help and co-operation given by Dr. J Rajasankar, Head and Dr. N. Anandavalli, project leader, Shock and Vibration group, CSIR-SERC, in fabricating the moulds and technical discussions during the field firing experiments is gratefully acknowledged. The permission and facilities provided by authorities of Officers Training Academy 
(OTA), Chennai for impact tests is highly acknowledged. This paper is being published with the permission of the Director, CSIR-Structural Engineering Research Centre, Chennai.

\section{References}

[1] Lankard D.R., Slurry Infiltrated Fiber Concrete (SIFCON) properties and applications", Materials Research Society Pittsburgh, 1985.

[2] Naaman A.E., Homrich J.R., Tensile Stress-Strain Properties of SIFCON, ACI Material Journal, 86(3), pp. 227-233, 1989.

[3] Parameswaran, V.S., Toughness of slurry infiltrated fibrous concrete (SIFCON), American Concrete Institute, SP-142, pp. 17-25, 1994.

[4] Maalej, M., Quek S. T. and Zhang, J., Behaviour of Hybrid-Fiber Engineered Cementitious Composites Subjected to Dynamic Tensile Loading and Projectile Impact, Journal of Materials in Civil Engineering, 17(2), pp. 143-152, 2005.

[5] Acebes M., Molero M., Segura I., Moragues A. and Hernandez M.G., Study of the Influence of Microstructural Parameters on the Ultrasonic Velocity in Steel-Fiber-Reinforced Cementitious Materials, Construction and Building Materials, 25, pp. 3066-3072, 2011.

[6] Chaix J.F., Garnier V. and Corneloup G., Concrete Damage Evolution Analysis by Backscattered Ultrasonic Waves, NDT\&E International, 36, pp. 461-469, 2003.

[7] Aggelis, D.G. and Shiotani, T., Repair Evaluation of Concrete Cracks using Surface and Through-Transmission Wave Measurements, Cement and Concrete Composites, 29, pp. 700-711, 2007.

[8] Breysse D., Klysz G., Dérober X., Sirieix C. and Lataste J.F., How to Combine Several Non-Destructive Techniques for A Better Assessment of Concrete Structures, Cement and Concrete Research, Vol. 38, 2008, pp. 783-793.

[9] Luo X., Sun W., Chan S.Y.N., Characteristics of High-Performance Steel Fiber-Reinforced Concrete Subjected to High Velocity Impact, Cem. and Con. Research, 30, pp. 907-914, 2000.

[10] Leppanen J., Dynamic behaviour of concrete structures subjected to blast and fragment impacts, Licentiate Thesis, Department of Structural Engineering, Division of Concrete Structures, Chalmers University of Technology, Göteborg, Sweden, pp. 71, 2002.

[11] Nyström U. and Gylltoft K., Comparative Numerical Studies of Projectile Impacts on Plain and Steel-Fibre Reinforced Concrete, International Journal of Impact Engineering, 38, pp. 95-105, 2011.

[12] Riedel W., Thoma K., Hiermaier S. and Schmolinske E., Penetration of Reinforced Concrete By Beta-B-500, Numerical Analysis Using A New Macroscopic Concrete Model for Hydrocodes, In: SKA (ed), Proceedings of the 9th International Symposium on Interaction of the Effects of Munitions with Structures, Berlin, 1999, pp. 315-322. 
[13] Sanjeev K. V., Sudhir S. B. and Saleem A., Review of Nondestructive Testing Methods for Condition Monitoring of Concrete Structures Review Article. Journal of Construction Engineering, http://dx.doi.org/10.1155/ 2013/834572. 2013

[14] Panzera T.H., Christoforo A.L., Cota F.P., Borges P.H.R. and Bowen C.R., Ultrasonic Pulse Velocity Evaluation of Cementitious Materials, Advances in Composite Materials - Analysis of Natural and Man-Made Materials, pp. 412-437, 2011.

[15] Popovics J. S., Song W., Achenbach J. D., Lee J. H., and Andre R. F., One-Sided Stress Wave Velocity Measurement in Concrete, Journal of Engineering Mechanics, 124(12), pp. 1346-1353, 1998.

[16] IS:13311 (Part 1): 1992 Non-destructive testing of concrete methods of test, part 1 ultrasonic pulse velocity, BIS, New Delhi.

[17] Borrvall T. and Riedel W. (2011) The RHT Concrete Model In LS-DYNA, 8th European LS-DYNA Users Conference, Strasbourg - May 2011.

[18] AUTODYN, (2009), Theory Manual (Version 12.0), Century Dynamics, Inc.; 2009. 